\title{
Análise da contaminação parasitária em compostos orgânicos produzidos com biossólidos de esgoto doméstico e resíduos agropecuários
}

\author{
Analysis of parasitological contamination in organic composts with sewage sludge and agricultural \\ residues
}

\author{
Eduardo Robson Duarte ${ }^{\mathrm{I}^{*}}$ Anna Christina Almeida ${ }^{\mathrm{I}}$ Bruna Lima Cabra ${ }^{\mathrm{II}}$ Flavia Oliveira Abrão ${ }^{\mathrm{II}}$ \\ Lincoln Nunes Oliveira ${ }^{\mathrm{II}}$ Marcelina Pereira da Fonseca" ${ }^{\mathrm{II}}$ Regynaldo Arruda Sampaio ${ }^{\mathrm{III}}$
}

\section{RESUMO}

Este estudo avaliou a contaminação por ovos de helmintos, cistos e oocistos de protozoários em compostos orgânicos utilizando lodo de esgoto doméstico e resíduos agropecuários. Foram realizadas análises parasitológicas em amostras de 25 diferentes compostos orgânicos, antes e após tratamento térmico a $60^{\circ} \mathrm{C}$ durante 12 horas. Os resultados demonstraram elevada contaminação parasitária em todos os compostos analisados antes do tratamento e a não redução dessa contaminação após o tratamento térmico. A identificação das larvas obtidas em coproculturas antes e após o tratamento térmico dos compostos indicou que os gêneros mais freqüentemente observados foram Cooperia e Trichostrongylus, que são nematóides gastrintestinais de ruminantes. Estes resultados demonstram que ovos de helmintos podem permanecer viáveis mesmo após o processo de compostagem e o tratamento térmico. Os compostos produzidos com lodo de esgoto doméstico e resíduo agropecuários, utilizando esses processos de tratamentos, podem constituir riscos de contaminação para humanos e animais.

Palavras-chave: lodo de esgoto, compostos orgânicos, parasitos, tratamento térmico.

\section{ABSTRACT}

This research aimed at evaluating the cysts, oocysts and eggs contamination before and after thermal treatment of $60^{\circ} \mathrm{C}$ for 12 hours, in 25 different organic composts produced with biosolids from domestic waste-water treatment and animal and agricultural residues. The results showed high parasitological contamination for all organic composts before the treatment and these contaminations were not reduced after thermic treatment. The larva identification in coprocultures before and after thermic treatment showed Cooperia spp. and Trichostrongylus spp. were the most prevalent nematodes. These results demonstrated that helmintus' eggs can remain viable even after the composing and thermic treatment. The obtained composition with sewage sludge and agricultural residues through these treatment processes can establish contamination risks for humans and animals.

Key words: sewage sludge, organic composts, parasites, thermic treatment.

\section{INTRODUÇÃO}

As atividades desenvolvidas pelo homem geram diariamente grande volume de resíduos provenientes de diversas áreas, aumentando a contaminação ambiental e os problemas de saúde pública. De acordo com as recomendações da World Health Organization (WHO), o efluente de reator de tratamento de esgoto doméstico pode ser utilizado na agricultura, desde que aplicado em culturas que apresentam poucos riscos de contaminação com agentes patogênicos (AYRES \& MARA, 1996). O biossólido do esgoto é ainda dividido em duas classes de acordo com a sua contaminação por patógenos. O de classe Aé resultante de processos de efetiva redução de patógenos, podendo ser utilizado na horticultura sem restrições, e o de classe B é resultante de processos de redução moderada de patógenos, com uso mais restrito, devendo ser aplicado em grandes culturas, reflorestamentos e outras situações em que o risco de contaminação ambiental e humana pode ser mais controlado (FERNANDES, 2000; DAVID, 2002).

\footnotetext{
IDepartamento de Zootecnia, Núcleo de Ciências Agrárias, Universidade Federal de Minas Gerais (UFMG). Av. Osmani Barbosa, s/ n, Bairro JK, 39400-006, Montes Claros, MG, Brasil. E-mail: duartevet@hotmail.com. *Autor para correspondência.

IICurso de graduação em Zootecnia, Núcleo de Ciências Agrárias, UFMG, Montes Claros, MG, Brasil.

IIIDepartamento de Fitotecnia, Núcleo de Ciências Agrárias, UFMG, Montes Claros, MG, Brasil.
} 
Os biossólidos devem possuir características que permitam seu enquadramento dentro dos parâmetros determinados para cada classe (DAVID, 2002). Para o lodo classe A, o número mais provável de coliformes fecais por grama de lodo seco deve ser inferior a 1000 e a contaminação parasitária deve ser menor que um ovo viável de helminto em quatro gramas do lodo seco e menor que um ovo por litro do efluente (WHO, 1989; FERNANDES, 2000).

Em virtude das dificuldades de se dar destino adequado aos resíduos de esgoto domésticos, vários países têm pesquisado alternativas para disposição final desses produtos. O esgoto, antes de passar por qualquer tipo de tratamento de estabilização e desinfecção, contém macro e micronutrientes e muitos microrganismos e parasitos. O manuseio e o emprego de esgoto e do lodo obtido, para os mais variados fins, sem prévio tratamento higienizante podem promover graves infecções ao homem e aos animais (PAULINO et al. 2001). Segundo a WHO, 25\% dos leitos hospitalares do mundo estão ocupados por pacientes com doenças veiculadas por água contaminada. É estimado que 1,5 bilhão de pessoas estejam infectadas com Ascaris lumbricoides e 1,3 bilhão com Ancilostomídeos (CROMPTON, 1999).

Os processos mais freqüentemente empregados para a estabilização de esgoto doméstico compreendem as digestões aeróbia e anaeróbia. A aplicação de cal e compostagem também são preconizadas por alguns países como Estados Unidos, França e Brasil. Entretanto, a eficiência dos processos de estabilização depende da qualidade operacional dos mesmos e da natureza dos patógenos presentes no lodo (PAULINO et al., 2001). Em sistemas de confinamento de bovinos leiteiros ou outros animais, um volume considerável de dejetos é gerado diariamente. Esses resíduos são ricos em matéria orgânica e em agentes patogênicos para bovinos e para humanos e são responsáveis pela poluição de águas superficiais e subterrâneas, carreando material pela ação das chuvas (DORAN \& LINN, 1979

Os dejetos de bovinos também são freqüentemente utilizados como fonte de adubação de forragens, entretanto, a simples aspersão desse material nas pastagens ou capineiras possibilita a continuidade do ciclo biológico dos nematódeos gastrintestinais, aumentando o potencial de contaminação e colocando em risco a saúde dos animais (DOWNEY \& MOORE, 1977). Assim, a adoção de práticas de manejo que visem minimizar a transferência de contaminantes às pastagens é de fundamental importância dentro de um sistema de produção (FURLONG \& PADILHA, 1996).
O presente trabalho teve como objetivo avaliar a contaminação por ovos, cistos e oocistos de protozoários em compostos orgânicos, utilizando biossólido de esgoto doméstico e resíduos agropecuários antes e após tratamento térmico.

\section{MATERIAL E MÉTODOS}

\section{Amostragem}

O experimento foi conduzido no Núcleo de Ciências Agrárias da Universidade Federal de Minas Gerais, localizado em Montes Claros, norte de Minas Gerais, latitude $16^{\circ} 51^{\prime} 38^{\prime}$ 'S e longitude 445' $00^{\circ}$ ' W, no período de agosto de 2006 a janeiro de 2007. Foram preparados 25 diferentes compostos orgânicos em galpão, onde permaneceram durante os primeiros quinze dias, sendo revirados e irrigados, quando necessário, em intervalos de dois dias. As medas de compostagem construídas para cada composto possuíam aproximadamente 0,5 metros cúbicos. Os compostos foram preparados com relações carbono/ nitrogênio de 25/1, 30/1, 35/1, 40/1 e 45/1. Na composição dos compostos, foram utilizados os resíduos de algodão (5,8 a 10\%), de sementes de milho e feijão (11,8 a $17,2 \%)$, e de sementes de capim (4,4 a 4,7\%). Foram também utilizados fibra de coco (5 a 20\%), casca de arroz (7,4 a 17\%), capim elefante (Pennisetum purpureum) picado (1,93 a 17,6\%), casca de pequi $(0,6$ a $2,27 \%$ ), esterco bovino fresco (2,3 a 4,8\%) e lodo de esgoto doméstico (28,8 a 38,1\%). O esterco utilizado foi proveniente de 40 vacas Holandesas com média de 5,5 anos e pertencentes ao rebanho da universidade. Cada composto recebeu $220 \mathrm{~g}$ de fosfato natural, $21 \mathrm{~kg}$ de gesso e $21 \mathrm{~kg}$ de calcário calcítico.

Primeiramente foram coletadas duas amostras de $500 \mathrm{~g}$ do lodo de esgoto proveniente da cidade de Juramento, no Norte de Minas Gerais. O lodo desidratado foi coletado no leito de secagem da Estação de Tratamento de Esgoto do município que utiliza Reator Anaeróbico de Fluxo Ascendente (RAFA). As análises físicas e químicas do lodo do esgoto analisado foram realizadas segundo técnicas preconizadas por TEDESCO et al. (1995) e indicaram que o lodo apresentava $\mathrm{pH}-\mathrm{H}_{2} 0$ 4,8, matéria orgânica com 16,2g $\mathrm{kg}^{-1}$ e teores de nitrogênio, carbono e umidade de $2,4 \%$, $9,42 \%$ e $6 \%$, respectivamente.

Posteriormente foram coletadas amostras de $500 \mathrm{~g}$ dos compostos ao décimo quinto dia de compostagem, evitando contaminações de um composto para outro e acondicionado-as em sacos plásticos limpos e livres da contaminação de parasitos. As amostras foram coletadas com auxílio de uma pá previamente lavada com detergente e desinfetada com hipoclorito de sódio a $10 \%$. 
Tratamento térmico

Após esse período, os compostos foram transferidos para uma estufa, onde foram submetidos a uma temperatura de $60^{\circ} \mathrm{C}$ durante 12 horas e mantidos em uma temperatura de $55^{\circ} \mathrm{C}$ até o vigésimo segundo dia após o tratamento. Esse procedimento foi empregado com o objetivo de promover a redução de patógenos dos compostos para serem empregados em olericultura e no cultivo de cogumelos comestíveis. Para verificar a eficácia do tratamento térmico e a sua uniformidade em todos os compostos produzidos, três amostras distintas de diferentes partes dos compostos, correspondendo às parcelas $\mathrm{A}, \mathrm{B}$ e C, foram coletadas após vinte e dois dias do fim do tratamento. Para isso foram obtidos $500 \mathrm{~g}$ para cada amostra, empregando as mesmas medidas higiênicas visando evitar a contaminação de uma parcela para outra.

Processamento das amostras e exames parasitológicos

Além de duas amostras do lodo de esgoto utilizado, foram coletadas ao todo 100 amostras dos compostos produzidos, sendo 25 antes do tratamento térmico e 75 após o tratamento, sendo três amostras distintas de cada um dos compostos elaborados (parcelas A, B e C).

No Laboratório de Parasitologia do NCA/ UFMG, as amostras dos compostos foram homogeneizadas uma a uma e 10 gramas foram pesados em balança de precisão e armazenados em frascos plásticos juntamente com $30 \mathrm{~mL}$ de solução de formaldeido $10 \%$ para conservação dos ovos, cistos e oocistos presentes.

Detecção de ovos de helmintos e cistos e oocistos de protozoários

Para quantificação dos ovos de helmintos, cistos e oocistos de protozoários, foi realizada a técnica de sedimentação dos sólidos durante 12 horas após a adição de água filtrada para completar o volume de um litro. Após esse procedimento, foi utilizado o Método de Bailenger, modificado por AYRES \& MARA(1996) preconizado pela WHO.

Depois de ocorrida a sedimentação, o sobrenadante foi eliminado com o auxílio de um sifão. Os sedimentos obtidos foram lavados com solução detergente (Lanolil 1\%) e recolhidos em tubos de centrífuga de $15 \mathrm{ml}$. Os sedimentos foram centrifugados durante 15 minutos e os sobrenadantes foram descartados. O volume obtido de sedimento foi tamponado em mesma relação v/v com solução tampão aceto-acética e homogeneizado com éter correspondendo ao dobro do volume obtido do sedimento. Após nova centrifugação durante 15 minutos, o sobrenadante foi novamente descartado e foi adicionado ao sedimento cinco vezes o seu volume em água destilada e novamente foi homogeneizada a solução. Foi retirado desse tubo um ml dessa solução e misturado a nove ml de solução de sulfato de zinco (densidade de 1,23). Foram montadas rapidamente duas câmaras McMaster e a contagem foi verificada no microscópio óptico em objetivas de 10X e 40X. Foram contados somente ovos com aspecto viável e posteriormente foi obtida a média aritmética das duas contagens. O número de ovos, cistos e oocistos por $\mathrm{kg}$ de composto foi obtido multiplicando o número médio das contagens das duas câmaras pelo volume em $\mathrm{ml}$ do sedimento final, dividindo por 0,30 (volume em $\mathrm{ml}$ dos dois retículos da câmara) e multiplicando por 1000 para obter a contagem por kg de composto (AYRES \& MARA, 1996).

Coprocultura quantitativa

Com o objetivo de verificar a viabilidade dos ovos observados na microscopia, foi realizada técnica de coprocultura quantitativa descrita por UENO, 1998. Foram pesados dois gramas das 25 amostras antes do tratamento térmico e dois gramas após o tratamento térmico (correspondendo às amostras das parcelas $\mathrm{B}$ dos compostos). O material foi homogeneizado com dois gramas de serragem seca autoclavada e umedecido com 10ml de solução de ácido sulfúrico a 1\% para controlar o crescimento de fungos. Após 28 dias de incubação em temperatura ambiente, utilizou-se a técnica de Baermann para coleta e a chave de KEITH (1953) para a identificação de 185 larvas provenientes de amostras dos compostos antes do tratamento térmico e 114 larvas após esse tratamento, respectivamente.

Análises estatísticas

Após a contagem de ovos e larvas de helmintos e de cistos e oocistos de protozoários dos 25 compostos analisados, os dados obtidos foram transformados em $\log (\mathrm{N}+1)$ e submetidos ao test $\mathrm{T}$ de Student a 5\% de probabilidade para comparação das médias obtidas antes e após o tratamento térmico (amostras da parcela B dos compostos). Os mesmos procedimentos foram aplicados para a comparação das médias obtidas entre as três diferentes parcelas dos compostos após o tratamento térmico com o objetivo de verificar a uniformidade deste processo em diferentes pontos de amostragem dos compostos.

\section{RESULTADOS E DISCUSSÃO}

Contaminação parasitária do biossólido utilizado Em duas amostras do biossólido provenientes de esgoto doméstico da cidade de 
Juramento, os resultados revelaram $1,2 \times 10^{4} \mathrm{ovos} \mathrm{g}^{-1} \mathrm{e}$ $1 \times 10^{4}$ cistos e oocisto $\mathrm{g}^{-1}$ da primeira amostra e 2,7x10 $0^{4}$ ovos e $2,7 \times 10^{4}$ cistos e oocistos $\mathrm{kg}^{-1}$ da segunda amostra, respectivamente. Não foram recuperadas larvas infectantes após a coprocultura quantitativa em amostras do biossólido utilizado, indicando que o processo de biodigestão anaeróbia do esgoto possa ter comprometido o desenvolvimento e a eclosão das larvas dos nematóides Ancilostomídeos.

Em regiões de clima quente, a utilização de reatores USAB (Upflow Anaerobic Sludge Blanket)é uma opção positiva para o tratamento de esgotos domésticos. Porém, os trabalhadores que manuseiam esses processos e os resíduos produzidos correm riscos potenciais de serem contaminados por parasitos (CARVALHO et al., 2003; SOUZA et al., 2006). Os efeitos da digestão anaeróbica e aeróbica, durante um período de 15 dias, sobre ovos de nematóides foram avaliados por BLACK et al. (1982). Os resultados indicaram que 23\% dos ovos dos Ascaris spp. foram destruídos no processo anaeróbico e $38 \%$ no aeróbico. Entretanto, o processo anaeróbico não teve efeito sobre ovos de Trichuris spp. e, para os ovos de Toxocara spp. nenhum dos processos foi eficiente.

Em um estudo na região metropolitana de Curitiba, Paraná, foi verificada a contaminação de biossólidos de esgoto obtidos em reatores anaeróbios de lodo fluidizado. Foram observadas reduções significativas quanto ao número de ovos viáveis de helmintos presentes no material de quatro diferentes estações estudadas, variando de 59,7 a 93\%. A eficácia do tratamento biológico com digestão anaeróbia foi influenciada pelo tempo e pela temperatura dos processos (PAULINO et al., 2001).

A eficácia dos sistemas de pós-tratamento Wetland, Leito de Brita não Vegetado e Lagoas de Polimento em efluentes de reator UASB da cidade de Campina Grande, Paraíba, foi avaliada. Os resultados indicaram que o esgoto bruto e o efluente do reator apresentaram 353,7 e 229,9 ovos por litro, respectivamente. Os três sistemas de pós-tratamento produziram efluentes isentos de ovos de helmintos e isso pôde ser justificado pela sedimentação produzida por uma carga hidráulica superficial de $0,20 \mathrm{~m} \mathrm{dia}^{-1}$ nas lagoas operadas (SOUZA et al., 2005).

Avaliação da contaminação parasitária antes e após o tratamento térmico dos compostos orgânicos produzidos

Na tabela 1 estão descritas a quantificação de larvas obtidas nas coproculturas, a contagem de ovos de helmintos e cistos e oocistos de protozoários em compostos orgânicos antes e após tratamento térmico. Esses resultados demonstram uma elevada contaminação parasitária de todos os compostos analisados e a análise estatística indicou a não redução dessa contaminação após o tratamento térmico de 12 horas a $60^{\circ} \mathrm{C}(\mathrm{P}<0,05)$. Os dados revelam também que todas as amostras apresentaram contaminação acima de um ovo por $4 \mathrm{~g}$ de composto, o que é preconizado para biossólidos classe A(FERNANDES, 2000).

Após a coprocultura das amostras obtidas dos compostos antes do tratamento térmico foi possível identificar que 52,4\% das larvas pertenciam ao gênero Cooperia, 36,7\% ao gênero Trichostrongylus, 7,1 \% ao gênero Bunostomum e 3,8\% ao gênero Haemonchus. Após o tratamento térmico, dos compostos, foi observado que 33,3\% das larvas pertenciam ao gênero Cooperia, 30,7\% ao gênero Trichostrongylus, 2,7\% a larvas filarioides de Strongyloides, que são comumente encontrados parasitando os ruminantes, e 33,3\% de larvas rhabditiformes do gênero Strongyloides, que representam formas de vida livre.

As duas amostras do lodo de esgoto e as 100 amostras dos compostos orgânicos apresentaram alta contagem de ovos de helmintos com aspectos viáveis, sob luz da microscopia óptica. Entretanto, na coprocultura foram recuperadas larvas de terceiro estádio somente nas amostras provenientes dos compostos e a identificação dos gêneros presentes sugeriu que a contaminação era proveniente do esterco bovino ou de resíduos agrícolas contaminados com ovos de helmintos de ruminantes. Em futuros estudos a contaminação prévia desses materiais deverá ser considerada para a análise de compostos orgânicos a serem produzidos.

A tabela 2 descreve a contagem de ovos, cistos e oocistos de protozoários de amostras de três parcelas distintas (A, B e C) de cada um dos 25 compostos após o tratamento térmico a $60^{\circ} \mathrm{C}$ durante 12 horas. Não foi observada diferença significativa entre as amostras do mesmo composto $(\mathrm{P}<0,05)$. Os resultados revelaram alta contagem dessas estruturas parasitárias em ambas as amostras obtidas dos compostos após o tratamento térmico, indicando que esse processo não foi efetivo na redução da contaminação parasitária em nenhum dos pontos amostrados.

Em outro estudo avaliaou o processo de biodigestão anaeróbica para tratamento de dejetos de bovinos utilizando-se a coprocultura, foram obtidos resultados positivos para larvas L3 de Haemonchus spp., Oesophagostomum spp. e Cooperia spp. nos efluentes, mesmo após quarenta dias de tempo de retenção (AMARAL et al., 2004). Entretanto, FURLONG \& PADILHA (1996) observaram efeito inativante da 
Tabela 1 - Contaminação parasitária em compostos orgânicos produzidos com lodo de esgoto e resíduos agropecuários antes e após tratamento térmico a $60^{\circ} \mathrm{C}$ durante 12 horas.

\begin{tabular}{|c|c|c|c|c|c|c|}
\hline \multirow{2}{*}{ Compostos } & \multicolumn{2}{|c|}{ Ovos x $10^{4} \mathrm{~kg}^{-1}$} & \multicolumn{2}{|c|}{ Larvas $\mathrm{x} 10^{4} \mathrm{~kg}^{-1}$} & \multicolumn{2}{|c|}{ cistos e oocistos $\times 10^{4} \mathrm{~kg}^{-1}$} \\
\hline & antes & após* & antes & após* & antes & após* \\
\hline 1 & 20,8 & 20 & 15,8 & 15,5 & 11 & 28 \\
\hline 2 & 22,6 & 4 & 7,8 & 8,0 & 27 & 8 \\
\hline 3 & 47,8 & 27 & 14,8 & 4,0 & 59 & 33 \\
\hline 4 & 65,3 & 10 & 17,8 & 3,0 & 83 & 4 \\
\hline 5 & 69 & 9 & 73,2 & 218,5 & 118 & 9 \\
\hline 6 & 67,5 & 33 & 4,2 & 4,5 & 21 & 27 \\
\hline 7 & 123,3 & 68 & 65 & 63,5 & 83 & 68 \\
\hline 8 & 6,3 & 8 & 45,6 & 26,0 & 2 & 24 \\
\hline 9 & 45 & 34 & 58,2 & 31,5 & 60 & 90 \\
\hline 10 & 36 & 45 & 8,2 & 11,0 & 87 & 268 \\
\hline 11 & 60 & 50 & 16,6 & 6,0 & 50 & 208 \\
\hline 12 & 77 & 46 & 35 & 11,5 & 238 & 124 \\
\hline 13 & 72 & 66 & 5,4 & 9,5 & 144 & 274 \\
\hline 14 & 24 & 60 & 15,8 & 12,5 & 69 & 222 \\
\hline 15 & 24 & 21 & 37 & 56,5 & 90 & 82 \\
\hline 16 & 12 & 12 & 9,4 & 11,5 & 52 & 73 \\
\hline 17 & 10 & 7,5 & 10,6 & 4,0 & 20 & 30 \\
\hline 18 & 9 & 2,5 & 40,8 & 306,0 & 13 & 12 \\
\hline 19 & 2 & 1 & 5,8 & 16,5 & 1 & 4,5 \\
\hline 20 & 15 & 6 & 9,8 & 18,0 & 15 & 25,5 \\
\hline 21 & 12 & 4 & 5,6 & 39,5 & 16 & 3 \\
\hline 22 & 5 & 10 & 85,8 & 4,5 & 11 & 8 \\
\hline 23 & 6 & 3 & 25,6 & 7,0 & 22 & 5 \\
\hline 24 & 10 & 4,5 & 7,8 & 66,0 & 17 & 16 \\
\hline 25 & 5 & 6 & 11,4 & 93,5 & 11 & 18 \\
\hline Média & 33,9 & 22,3 & 25,32 & 41,92 & 52,8 & 66,56 \\
\hline Desvio padrão & 31,3 & 21,2 & 23,6 & 71,5 & 54,56 & 82,3 \\
\hline
\end{tabular}

*Contagem das amostras das parcelas B dos compostos orgânicos coletadas após o tratamento térmico.

anaerobiose próximo a $100 \%$, com o tempo de retenção acima de 56 dias e, segundo OLSON \& NANSEN (1987), a digestão anaeróbia mesofílica $\left(35^{\circ} \mathrm{C}\right)$ e a termofílica $\left(53^{\circ} \mathrm{C}\right)$ aceleraram o processo de inativação de nematóides em relação ao tempo de sobrevivência desses parasitos no armazenamento convencional. A variação nesses dados de redução de contaminação parasitária nos produtos obtidos por processos de digestão anaeróbia indica a necessidade de novos estudos, padronizando e monitorando esses resíduos para reciclagem na agricultura ou para outros objetivos, visando reduzir os riscos para saúde pública e animal.

Os dados obtidos em nossos estudos indicam que, mesmo após a compostagem e tratamento térmico, os ovos de parasitos podem permanecer viáveis e produzir larvas infectantes. Os compostos produzidos neste estudo poderiam ser classificados na classe C, para uso em culturas com poucos riscos de contaminação em relação a organismos patogênicos, como algodão, pomares, reflorestamentos. Esses compostos também não deveriam ser aplicados em pastagens dos ruminantes, uma vez que poderiam constituir fonte de contaminação para nematóides gastrintestinais desses animais. A utilização dos compostos com resíduos de esgoto doméstico na adubação de pastagens de bovinos também não deveria ser indicada, pois poderia constituir risco para a contaminação desses animais com ovos de Taenia sarginata, contribuindo na permanência do ciclo da cisticercose bovina e teníase em humanos.

\section{CONCLUSÕES}

Os resultados obtidos demonstram que, mesmo após a compostagem de resíduos agropecuários com biossólido do esgoto doméstico e após o tratamento térmico a $60^{\circ} \mathrm{C}$, durante 12 horas, grande número de ovos de helmintos pode permanecer viável. 
Tabela 2 - Contaminação com ovos de helmintos e cistos e oocistos de protozoários em três diferentes amostras de compostos orgânicos produzidos com lodo de esgoto doméstico e resíduos agropecuários após tratamento térmico a $60^{\circ} \mathrm{C}$ durante 12 horas.

\begin{tabular}{|c|c|c|c|c|c|c|}
\hline \multirow{2}{*}{ Compostos } & \multicolumn{3}{|c|}{ 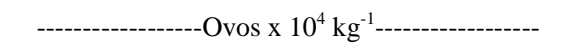 } & \multicolumn{3}{|c|}{--------cistos e oocistos x $10^{4} \mathrm{~kg}^{-1}-$} \\
\hline & Parcela A & Parcela B & Parcela C & Parcela A & Parcela B & Parcela C \\
\hline 1 & 19 & 20 & 7 & 9 & 28 & 13 \\
\hline 2 & 16 & 4 & 5 & 19 & 8 & 10 \\
\hline 3 & 23 & 27 & 55 & 23 & 33 & 10 \\
\hline 4 & 62 & 10 & 32 & 27 & 4 & 18 \\
\hline 5 & 60 & 9 & 28 & 23 & 9 & 15 \\
\hline 6 & 20 & 33 & 13 & 15 & 27 & 24 \\
\hline 7 & 10 & 68 & 13 & 42 & 68 & 124 \\
\hline 8 & 2 & 8 & 14 & 7 & 24 & 38 \\
\hline 9 & 7 & 34 & 3 & 46 & 90 & 51 \\
\hline 10 & 13 & 45 & 9 & 43 & 268 & 29 \\
\hline 11 & 3 & 50 & 4 & 23 & 208 & 12 \\
\hline 12 & 10 & 46 & 6 & 9 & 124 & 20 \\
\hline 13 & 5 & 66 & 3 & 10 & 274 & 27 \\
\hline 14 & 20 & 60 & 4 & 56 & 222 & 32 \\
\hline 15 & 11 & 21 & 9 & 43 & 82 & 27 \\
\hline 16 & 6 & 12 & 8 & 44 & 73 & 19 \\
\hline 17 & 1 & 7,5 & 4 & 23 & 30 & 106 \\
\hline 18 & 3 & 2,5 & 7 & 42 & 12 & 103 \\
\hline 19 & 3 & 1 & 15 & 8 & 4,5 & 34 \\
\hline 20 & 4 & 6 & 1 & 9 & 25,5 & 8,5 \\
\hline 21 & 15 & 4 & 7 & 62 & 3 & 32 \\
\hline 22 & 32 & 10 & 2 & 270 & 8 & 26 \\
\hline 23 & 3 & 3 & 6 & 6 & 5 & 6 \\
\hline 24 & 9 & 4,5 & 10 & 36 & 16 & 46 \\
\hline 25 & 23 & 6 & 10 & 60 & 18 & 65 \\
\hline Média & 15,2 & 22,3 & 11,04 & 38,2 & 66,56 & 35,82 \\
\hline Desvio padrão & 16 & 21,2 & 11,5 & 51,4 & 82,3 & 31,7 \\
\hline
\end{tabular}

A utilização dos compostos deve ser destinada a culturas perenes e de baixo risco de contaminação para animais e humanos, não sendo então recomendada para pastagens dos ruminantes, para a olericultura ou para a produção de cogumelos comestíveis.

\section{AGRADECIMENTOS}

O trabalho foi desenvolvido com o apoio financeiro do FUNDECI/Banco do Nordeste do Brasil, Conselho Nacional de Desenvolvimento Científico e Tecnológico (CNPq) e do Núcleo de Ciências Agrárias do UFMG.

\section{REFERÊNCIAS}

AMARAL, C.V. et al. Biodigestão anaeróbia de dejetos de bovinos leiteiros submetidos a diferentes tempos de retenção hidráulica. Ciência Rural, Santa Maria, v. 36, 1897-1902, 2004.

AYRES R, MARA, D. Analysis of wastewater for use in agriculture. A laboratory manual of parasitological and bacteriological techniques. Geneva: WHO, 1996. 31p. BLACK, M.I. et al. Survival rates of parasite eggs in sludge during aerobic and anaerobic digestion. Applied
Environmental Microbiology, Washington, v.44, p.11381143, 1982.

CARVALHO, J.B. et al. Presença de ovos de helmintos em hortaliças fertilizadas com lodo de lagoa de estabilização. Revista Brasileira de Análises Clínicas, Rio de Janeiro, v.35, p.101-103, 2003.

CROMPTON, D.W.T. How much human helminthiasis is there in the world? Journal of Parasitology, Lawrence, v.85, p.379-403, 1999.

DAVID, A.C. Secagem térmica de lodos de esgoto. Determinação da umidade de equilíbrio. 2002. $151 \mathrm{f}$. Dissertação (Mestrado) - Escola Politécnica da Universidade de São Paulo, São Paulo.

DORAN, J.W.; LINN, D.M. Bacteriological quality of run off water from pastereland. Applied Microbiology, Washington, v.37, p.985-991, 1979.

DOWNEY, N.E.; MOORE, J.F. Trichostrongylid contamination of pasture fertilized with cattle slurry. Veterinary Record, London, v.101, n.24, p.487-488, 1977. FERNANDES, F. Estabilização e higienização de biossólidos. In: BETTIOL, W.; CAMARGO, O.A. (Eds). Impacto 
ambiental do uso agrícola do lodo de esgoto. Jaguariúna: EMBRAPA Meio Ambiente, 2000. p.45-67.

FURLONG, J.; PADILHA, T. Viabilidade de ovos de nematódeos gastrintestinais de bovinos após passagem em biodigestor anaeróbio. Ciência Rural, Santa Maria, v.26, p.269-271, 1996.

KEITH R.K. The differentiation of the infective larvae of some common nematode. Australian, Journal of Zoology, Collingwood, v.1, p.223-235, 1953.

OLSON, J.E.; NANSEN, P. Inactivation of some parasites by anaerobic digestion of cattle slurry. Biological Wastes, Fayetteville, v.22, p.107-114, 1987.

PAULINO, R.C. et al. Tratamento anaeróbio de esgoto e sua eficiência na redução da viabilidade de ovos de helmintos. Revista da Sociedade Brasileira de Medicina Tropical, Uberaba, v.34, p.421-428, 2001.

SOUSA, J.T. et al. Reuso de água residuária na produção de pimentão (Capsicum annuum L.). Revista Brasileira de
Engenharia Agrícola e Ambiental, Campina Grande, v10, p.89-96, 2006.

SOUSA, J.T. et al. Tratamento de esgoto para uso na agricultura do Semi-Árido Nordestino. Engenharia Sanitária Ambiental, Rio de Janeiro, v.10, p.260-265, 2005.

TEDESCO, M.J. et al. Análise de solo, plantas e outros materiais. 2.ed. Porto Alegre: Departamento de Solos/UFRGS, 1995. 174p. (Boletim Técnico, 5).

UENO, H.; GONÇALVES, P.C. Manual para diagnóstico das helmintoses de ruminantes. 4.ed. Tokio: Japan International Cooperation Agency, 1998. 143p.

WORLD HEALTH ORGANIZATION. Health guidelines for the use of wastewater in agriculture and aquaculture. Technical report series. 778. Geneva: WHO, 1989. 72p. 
O arquivo disponível sofreu correções conforme ERRATA publicada no Volume 38 Número 9 da revista. 